\title{
The Law of Peoples \\ A Utopia Realista Rawlsiana e a Ideia de Justiça Social entre os Povos
}

\author{
Anna Paula Bagetti Zeifert \\ Doutora em Filosofia (PUCRS). Professora do Programa de Pós-Graduação em Direito - Mestrado em Direitos Humanos \\ e do curso de Graduação em Direito da Unijuí. Integrante do Grupo de Pesquisa Direitos Humanos, Globalização e Equidade (CNPq). \\ Coordenadora do projeto de pesquisa "Justiça Social: os desafios das políticas sociais na realização das necessidades humanas \\ fundamentais". annazeifert@yahoo.com.br
}

No presente artigo analisamos como o projeto de justiça social rawlsiano, pensado inicialmente para as sociedades nacionais, foi estendido para a Sociedade dos Povos na obra The Law of Peoples. Examinamos como John Rawls resgata e apresenta seus elementos essenciais na proposta de justiça entre os povos, e sua preocupação em garantir estabilidade e o mínimo de justiça social no interior das sociedades que integram a Sociedade dos Povos. Ponderamos como seus objetivos se encontram interligados tanto na proposta de justiça política para o interior dos Estados quanto na relação entre Estados, garantindo a legitimidade das sociedades a partir de uma estrutura básica e de instituições justas. Nesse contexto, nosso objetivo é demonstrar que, ao pensar esse processo paralelo de justiça (nacional e internacional) e projetar uma segunda posição original, guiando para seus elementos essenciais com vistas à promoção da justiça social entre os povos, Rawls também apresenta os limites da sua realistic utopia e os caminhos para a reconciliação do indivíduo com o mundo social ao qual pertence. $O$ estudo foi desenvolvido com base no método de abordagem hipotético-dedutivo, utilizando uma base teórica presente na filosofia política contemporânea.

Palavras-chave: Justiça Social. Estabilidade. Sociedade dos povos.

THE LAW OF PEOPLES RAWLSIAN REALISTIC UTOPIA AND THE IDEA OF SOCIAL JUSTICE AMONG PEOPLES

\section{ABSTRACT}

In this paper we analyze how the Rawlsian social justice project, originally intended for national societies, was extended to the Peoples' Society in The Law of Peoples. We examine how John Rawls rescues and presents its essential elements in the proposal of justice among peoples, their concern to guarantee stability and the minimum of social justice within the societies that comprise the Society of Peoples. We consider how their objectives are interconnected both in the proposal of political justice for the interior of the States and in the relation between States, guaranteeing the legitimacy of societies from a basic structure and just institutions. In this context, our goal is to demonstrate that by thinking about this parallel process of justice (national and international), and projecting a second, original position, guide to its essential elements for the promotion of social justice among peoples, Rawls also presented the limits of its realistic utopia and the ways to the reconciliation of the individual with the social world to which he belongs. The study was developed based on the hypothetical-deductive approach method, using a theoretical basis present in contemporary political philosophy.

Keywords: Social justice. Stability. Society of peoples.

\section{SUMÁRIO}

1 Considerações iniciais. 20 protagonismo dos povos democráticos, liberais e decentes na Sociedade dos Povos. 3 A posição original em dois níveis: pensando os elementos essenciais para uma concepção política de justiça na esfera internacional. 4 Considerações finais. 5 Referências. 


\section{CONSIDERAÇÕES INICIAIS}

A noção de sociedade justa, que tem como objetivo a estabilidade das relações sociais e das suas instituições, necessariamente está pautada pela convivência pacífica das mais diversas doutrinas morais abrangentes. O fato de o pluralismo razoável ser parte da história dessas sociedades, favorece a sua organização e a afirmação das condições de igualdade e liberdade entre os cidadãos. Não seria diferente se pensássemos essa sociedade na esfera internacional; a sociedade dos povos razoáveis, também inseridos em um contexto de muitas doutrinas morais em virtude de culturas, crenças, pensamentos e tradições das mais variadas. "Esse fato do pluralismo razoável limita o que é possível praticamente aqui e agora [e sua existência] não deve ser motivo de arrependimento [visto que ele] permite uma sociedade de maior justiça política e liberdade." Para o autor americano, é essa forma de argumentação que permitiria uma reconciliação ${ }^{1}$ com a condição política e social contemporânea (RAWLS, 2001, p. 25).

É nessa perspectiva que o Rawls verifica a viabilidade da sua realistic utopia ${ }^{2}$ para o âmbito internacional e, também, o seu limite, sempre considerando a reconciliação do indivíduo com o mundo social ao qual pertence. ${ }^{3}$ Essas são algumas das pretensões do autor ao apresentar as condições de "possibilidade de uma democracia constitucional razoavelmente justa no contexto de uma sociedade dos povos bem ordenada" (CABRITA, 2012, p. 78).

O autor americano retoma as considerações feitas para as sociedades no âmbito interno, de maneira a verificar se tais condições poderiam ter validade em uma "sociedade dos povos razoavelmente justos e decentes, que honrassem o Direito dos Povos" (CABRITA, 2012, p. 78-79). Caso essas condições se confirmem, a Sociedade dos Povos também poderia ser pensada como uma utopia realizável.

Para tanto, Rawls (2001) elenca algumas condições para que uma utopia realista possa existir:

i) para que uma concepção liberal seja realista são necessárias duas condições: que a estabilidade seja garantida por meio das leis e "que os seus princípios e preceitos sejam funcionais e aplicáveis a arranjos políticos e sociais em andamento"; nesse caso o autor está a se referir aos bens primários elencados na justiça como equidade (RAWLS, 2001, p. 18);

\footnotetext{
Expressão utilizada por Cabrita (2012, p. 78) no artigo "Os desígnios da democracia global internacional na utopia realista rawlsiana".

2 Para Oliveira (2003, p. 42), a proposta rawlsiana de uma realistic utopia é um resgate dos “[...] ideais da paz perpétua advogada por Saint-Pierre, Rosseau e Kant no século XVIII [...] enquanto alternativa concreta a uma pax americana que, assim como a pax Roman há dois milênios, carece de fundamentos normativos pela própria imposição de interesses econômicos particulares. Rawls é implacável nas suas críticas à política externa americana, desde o uso de bombas atômicas contra a população civil de Hiroschima e Nagasaki até a intervenção desastrosa contra regimes democráticos [...] por interesses econômicos e idológicos de 'segurança nacional'."

3 Para Rawls (2001, p. 12), "A ideia básica é seguir o exemplo de Kant tal como esboçado por ele na Paz perpétua"; Para compreender a diferença entre a posição rawlsiana e a posição kantiana, é interessante ver a seguinte passagem da obra de Oliveira (1998, p. 122): "Enquanto o construtivismo moral de Kant reivindica pretensões de validez como uma 'doutrina abrangente' ('comprehensive moral view'), o construtivismo político de Rawls apenas representa um modelo teórico capaz de estabelecer um consenso mínimo necessário para que diferentes doutrinas morais, filosóficas e religiosas possam coexistir numa sociedade democrático-liberal, numa concepção razoável de pluralismo."
} 
ii) uma concepção política de justiça será utópica quando usar de princípios, ${ }^{4}$ ideias e conceitos que especifiquem as condições para uma sociedade ser justa e razoável. Tais princípios irão colaborar para a estabilidade da sociedade, garantindo termos equitativos de cooperação entre os cidadãos, satisfazendo os critérios de reciprocidade. São esses princípios, também, no todo ou em parte, que fazem parte de um rol de direitos liberais que deverão pautar os rumos de uma sociedade que se pretenda liberal;iii) é fundamental que uma concepção política de justiça contenha todos os elementos essenciais para sua formatação, e jamais seja conduzida por concepções morais abrangentes e sim por ideias políticas;

iv) em razão do fato do pluralismo, as instituições sociais e políticas, em uma sociedade democrática constitucional, devem conduzir seus cidadãos (desde o nascimento) a seguir um sentido político de justiça e agir conforme suas diretrizes, o que garantiria estabilidade às relações sociais; ${ }^{5}$

v) toda a unidade social está construída a partir de uma concepção política de justiça endossada por um overlapping consensus entre doutrinas morais abrangentes;

vi) a necessidade de tolerância, tendo em vista que é sabido que no interior de uma sociedade nem todos os cidadãos seguem uma mesma concepção do bem. Essa noção de tolerância emerge da própria concepção política de justiça ou das doutrinas morais razoáveis que compõem a sociedade, o que evidencia "a razoabilidade da tolerância pela razão pública" (RAWLS, 2001, p. 22).

Estabelecidas as condições de existência de uma realistic utopia em uma sociedade razoavelmente justa, cabe verificar como estas condições apresentam-se na Sociedade dos Povos.

Na primeira condição, entende o autor que uma Sociedade dos Povos, dita justa e bem ordenada, é realista da mesma forma que uma sociedade liberal ou decente. É necessário organizar a Sociedade dos Povos, visando a promover a cooperação, a liberdade e a igualdade de todos os povos.

Na segunda condição, Rawls (2001) descreve que um Direito dos Povos, justo e razoável, é utópico, posto que utiliza várias ideias, princípios e conceitos (morais) políticos para especificar os arranjos políticos e sociais razoavelmente certos e justos para a Sociedade dos Povos. Já a terceira condição diz respeito à necessidade de que os elementos essenciais de uma concepção política de justiça sejam pertencentes ao campo do político; no caso do Direito dos Povos, que essa concepção esteja presente como forma de garantir a estabilidade das relações entre os povos. Essas relações deveriam estar sempre pautadas por uma concepção política liberal de justiça, capaz de sustentar uma democracia constitucional.

\footnotetext{
${ }^{4}$ Conforme Rawls (2001), há um conjunto de princípios ligados à concepção liberal razoável de justiça. Podemos dividi-los em três grupos distintos: o primeiro trata dos direitos e liberdades básicas numa democracia constitucional; o segundo leva em conta a necessidade de considerar prioritários os direitos de liberdades e oportunidades; e o terceiro e último, garante que todos os cidadãos tenham acesso aos bens primários necessários para que exerçam de forma plena suas liberdades.

5 Entende Rawls (2001, p. 20-21) que "na medida em que as concepções liberais exigem a conduta virtuosa dos cidadãos, as virtudes (políticas) necessárias são as de cooperação política, tais como um senso de imparcialidade e tolerância, e disposição para soluções de compromisso com os outros. A estrutura das instituições políticas permanece justa e estável (pelas razões certas) ao longo do tempo."
} 
O reasonable pluralism, quarta condição para a estabilidade da sociedade dos povos, "é mais evidente em uma sociedade de povos bem ordenados do que em apenas uma sociedade." Deve haver, no entanto, entre os membros de uma sociedade, senso suficiente de justiça e, da mesma forma, apoio a um governo que honre o Direto dos Povos. Tais constatações nos encaminham para as duas últimas condições: a quinta condição, que entende que "a unidade de uma Sociedade dos Povos razoáveis não exige unidade religiosa", ou seja, na razão pública, na Sociedade dos Povos, assim como numa sociedade democrática, os seus conteúdos são orientadores dos princípios de justiça; e, por fim, a sexta e última condição, quando "o argumento a favor da tolerância, derivado da ideia do razoável, é igualmente válido na sociedade dos Povos [...]", em razão de que tal sociedade é ainda mais complexa pelo número de doutrinas morais abrangentes que se encontram em evidência, o que "torna inevitável que daí advenha a tolerância, se os povos-membros [da Sociedade dos Povos] empregam a razão pública nos tratos mútuos" ${ }^{\prime 6}$ (RAWLS, 2001, p. 24-25).

Assim sendo, nossa intenção é rever os argumentos rawlsianos para a construção de sua realistic utopia na obra The Law of Peoples (1999), o caminho percorrido pelo autor ao tentar explicitar a sua teoria da justiça para a esfera internacional, bem como a sua teoria ideal de justiça política e social. Mais especificamente, compreender como Rawls, considerando a realidade das sociedades, tanto na esfera nacional quanto na internacional, busca colaborar para a construção de uma sociedade mais justa, democrática, igualitária e liberal.

\section{O PROTAGONISMO DOS POVOS DEMOCRÁTICOS, LIBERAIS E DECENTES NA SOCIEDADE DOS POVOS}

Segundo Rawls (2001), é necessário que os povos aprendam "a coordenar as ações dos seus governos em formas mais amplas de cooperação política, econômica e social", de maneira a possibilitar a existência de uma sociedade razoavelmente justa de povos bem ordenados capaz de influenciar uma teoria política internacional de diretos e promoção da paz. ${ }^{7}$

A teoria contratualista rawlsiana, inicialmente elaborada para o âmbito interno das sociedades liberais democráticas, apresenta-se, em The Law of Peoples, como uma proposta semelhante de justiça liberal igualitária, porém mais global, desenvolvida para uma concepção política de direito e de justiça específica para a sociedade internacional. A partir dela, o autor analisa a viabilidade ou não de realização da sua "utopia realista", que também se apresenta como um projeto de justiça social "[...] que combina o direito político e a justiça para todos os povos liberais e decentes em uma Sociedade dos Povos." Não podemos esquecer que Rawls, ao longo da sua obra, irá testar a viabilidade da sua teoria para sociedades que se encontram

\footnotetext{
Em Rawls (2001, p. 25) "a ideia de razão pública para a Sociedade dos Povos é análoga à ideia de razão pública no caso interno."

Rawls (2001, p. 29-30) comenta, na sua obra, sobre alguns males do passado e do presente que poderiam, de certa forma, influenciar um pensamento negativo sobre a sua proposta de uma utopia realista e sua possível concretização. Entre esses acontecimentos históricos que marcaram profundamente a sociedade internacional, está o Holocausto. No entender do autor, porém, "não devemos permitir que esses grandes males do passado e do presente solapem a nossa esperança no futuro da nossa sociedade, pertencente a uma Sociedade de Povos Liberais e decentes ao redor do mundo. Antes, devemos sustentar e fortalecer a nossa esperança, desenvolvendo uma concepção razoável e funcional de direito político e justiça que se aplique às relações entre os povos."
} 
em situações desfavoráveis, tanto sob o ponto de vista econômico quanto da paz. Um dos elementos inseridos pelo autor está representado pelo princípio oitavo do Direito dos Povos, denominado dever de assistência (RAWLS, 2001, p. 7).

Nesse contexto, sua proposta tem como principais objetivos: a) analisar "como cidadãos e povos razoáveis podem viver pacificamente num mundo justo"; b) assim como, desenvolver "os ideais e princípios da política exterior de um povo razoavelmente justo, mediante uma concepção razoável e funcional de direito político e de justiça que se aplique às relações entre os povos"; c) levar "a concepção política liberal de regime democrático constitucional a um segundo nível" (pacto entre os representantes de povos liberais); e, por fim, d) estabelecer, por meio de uma associação de povos bem-ordenados (liberais e decentes), a "cooperação política, econômica e social, regulada por organizações tais como as Nações Unidas" (RAWLS, p. 2001, p. XII-XIII).

Em The Law of Peoples, Rawls pretende apresentar como seria possível uma Sociedade mundial dos povos liberais, impulsionado pela ideia de uma justiça política discutida inicialmente em A Theory os Justice (1999) e em Political Liberalism (1993). Ele evidencia que uma sociedade política somente será efetivamente democrática quando conseguir estabelecer quais são suas prioridades e como irá chegar até elas. Para o autor americano, é por meio da sua razão (razão pública) que uma sociedade acessa tais questões, por isso a importância de um consenso em torno daquilo que é fundamental para os cidadãos.

Nesse sentido, a utopia realista rawlsiana expõe saídas para algumas questões, tais como a guerra injusta, a opressão, a perseguição religiosa, a negação da liberdade de consciência, a fome, a pobreza, o genocídio, o assassinato em massa, entre outras. Para o autor, esses problemas seriam superados por meio de políticas sociais justas e instituições básicas justas, ${ }^{8}$ visando a atingir uma sociedade razoável e decente, porventura liberal. Assim, "o objetivo central de The Law of Peoples seria plenamente alcançado quando todas as sociedades tivessem conseguido estabelecer um regime liberal ou decente, por mais improvável que isso possa ser" (RAWLS, 2001, p. 6).

Supõe como forma de argumento, "que se crescemos sob uma estrutura justa, afirmaremos essas instituições quando envelhecermos e elas persistirão ao longo do tempo". Desse modo, "o respeito à liberdade religiosa e à liberdade de consciência, à liberdade política, às liberdades constitucionais e à igual justiça para as mulheres são aspectos fundamentais de política social judiciosa" que, segundo Rawls (2001, p. 7-8), representariam pontos favoráveis para uma utopia realista.

Nesse contexto, Rawls (2001) elenca cinco tipos de sociedades nacionais que compõem a Sociedade dos Povos: 1 - Povos liberais razoáveis; 2 - Povos decentes ou povos hierárquicos decentes; 3 - Estados fora da lei; 4 - Sociedades sob o ônus de condições desfavoráveis; 5 Absolutismos benevolentes. É desde a concepção de tais sociedades que Rawls passará a dis-

\footnotetext{
8 Destacamos esta frase para afirmar que, mais uma vez, o ideal igualitário está presente em Rawls. Em The Law of Peoples, a estrutura básica das sociedades nacionais será novamente retomada como um elemento fundamental, aliado à ideia de justiça social por meio de políticas sociais. A necessidade de que as instituições sejam justas liga-se à proposta de sociedade bem-ordenada e cooperativa, conforme Rawls já havia determinado no seu projeto para as sociedades nacionais.
} 
cutir a questão da tolerância, dos direitos humanos, da guerra justa e de justiça social a partir do dever de assistência, esse último objeto específico do presente estudo, mas sem negar a sua relação profunda com os demais temas abordados.

Rawls fixa como atores da sua proposta para a Sociedade dos Povos, os povos e não os Estados. ${ }^{9} \mathrm{O}$ protagonismo dos povos (liberais, democráticos e decentes) se assemelha muito a sua proposta para as sociedades nacionais; nesse caso, porém, os cidadãos são peça-chave para o desenvolvimento e efetivação de uma sociedade política justa e bem-ordenada. ${ }^{10}$ No caso da Sociedade dos Povos, o autor americano descreve os povos como responsáveis e não os Estados, ${ }^{11}$ cabendo a eles promover a justiça e o reconhecimento igual aos demais povos (RAWLS, 2001).

Algumas características, segundo o autor, estão presentes quando se está a tratar de povos liberais. A primeira delas diz respeito à organização do seu poder por meio de um governo constitucional justo e razoável, sempre respeitando os direitos fundamentais de cada um dos seus membros. ${ }^{12} \mathrm{~A}$ segunda característica é a união entre cidadãos, o que influencia a cooperação e o respeito mútuo. ${ }^{13} \mathrm{~A}$ terceira e última característica é a "natureza moral" ${ }^{14}$, ou seja, todas as ações são motivadas por uma concepção política de justiça e de direito. Para o autor, é fundamental compreender como essa natureza moral irá se efetivar e passar de geração em geração.

Os povos liberais, contudo têm realmente os seus interesses fundamentais, permitidos pelas suas concepções de direito e de justiça. Buscam proteger o seu território, garantir a segurança dos seus cidadãos, preservar suas instituições políticas livres e as liberdades e a cultura livre da sua sociedade civil. Além desses interesses, um povo liberal tenta assegurar justiça razoável para todos os seus cidadãos e para todos os povos; um povo liberal pode viver com outros povos de caráter semelhante sustentando a justiça e preservando a paz. Qualquer esperança que tenhamos de chegar a uma utopia realista baseia-se em haver regimes constitucionais liberais (e decentes) razoáveis suficientemente instalados e eficazes para resultar em uma Sociedade dos Povos viável (RAWLS, 2001, p. 38).

\footnotetext{
9 Entende Cabrita (2012, p. 83) que "[...] os povos justos estão preparados para garantir o mesmo respeito e reconhecer os outros como seus iguais no seio da sociedade internacional."

${ }^{10}$ A relevância de escolher povos e não Estado para serem protagonistas da sociedade na esfera internacional se deve ao fato de que ambos se caracterizam por serem motivados por questões morais que poderiam colaborar para as relações com vistas à cooperação (PETTIT, 2007).

11 "Os Estados são atores em muitas teorias de política internacional a respeito das causas da guerra e da preservação da paz. Muitas vezes são vistos como racionais, ansiosamente preocupados com seu poder [...] Se a racionalidade exclui o razoável [...] se a preocupação de um Estado com o poder é predominante [...] então a diferença entre Estados e povo é enorme. Interesses como esses tendem a colocar um Estado em confronto com outros" (RAWLS, 2001, p. 36-37, grifo do autor).

${ }^{12}$ Nesse caso, compreende Rawls (2001, p. 31) que "[...] o governo está eficazmente sob o controle político e eleitoral, que responde pelos seus interesses fundamentais e que os protege como especificado em uma constituição escrita ou não escrita."

${ }^{13}$ Para Rawls (2001, p. 32), "as conquistas históricas e a imigração causaram a mistura de grupos com culturas e memórias históricas diferentes, que agora residem no território da maioria dos governos democráticos contemporâneos. [...] o Direito dos Povos parte da necessidade de afinidades comuns, não importa qual a sua fonte."

${ }^{14}$ Entende o autor americano que, assim "como cidadãos razoáveis na sociedade nacional oferecem-se para cooperar em termos imparciais com outros cidadãos, os povos liberais (ou decentes) (razoáveis) oferecem termos de cooperação justos a outros povos" (RAWLS, 2001, p. 33).
} 
Identificamos em Rawls uma certa tendência à "democracia global", que, no entender de Cabrita (2012, p. 84-85), teria por base a proposta de uma "paz democrática" e de "direitos humanos". A primeira questão, relativa à "paz democrática", estaria presente quando o autor analisa a questão dos conflitos bélicos e a necessidade de paz entre as nações, que somente seria garantida pela paz e pela estabilidade interna das sociedades, o que resultaria em uma paz e uma estabilidade estendida à sociedade internacional. A segunda questão, que envolve os direitos humanos, se traduz pela sua proposta de uma "confederação de povos, com um papel similar ao das Nações Unidas, e que exerça uma espécie de vigília sobre o mundo", alertando a sociedade internacional sobre possíveis violações da dignidade humana por regimes opressores e suas instituições injustas.

Rawls (2001, p. 46) entende ser necessária a adoção de certos princípios de igualdade entre os povos, que abrirão espaço para "várias formas de associações e federações cooperativas" entre eles, mas não afirmarão um Estado mundial." Defende que é preciso estabelecer uma segunda posição original, no entanto observa que a primeira posição original e a segunda posição, proposta para a sociedade dos povos, não seriam análogas.

\section{A POSIÇÃO ORIGINAL EM DOIS NÍVEIS:}

\section{Pensando os Elementos Essenciais para uma}

\section{Concepção Política de Justiça na Esfera Internacional}

A ideia de uma posição original (primeiro nível) é apresentada por Rawls, primeiramente, em $A$ Theory of Justice, quando propõe a construção de uma sociedade justa e equânime. Estabelece que a mesma surja a partir de um acordo entre cidadãos livres e iguais, ${ }^{15}$ que, na posição original - condição de possibilidade para a escolha dos princípios, sob um véu da ignorância - irão estabelecer princípios para a convivência de todos os cidadãos e que, da mesma forma, serão orientadores das instituições políticas, sociais e econômicas em um Estado Democrático. Esse consenso em torno de uma concepção política de justiça na esfera estatal é ponto de discussão também na obra Political Liberalism, momento em que o autor reafirma a sua concepção política de justiça e busca uma harmonia entre o conjunto de doutrinas morais abrangentes que compõe as sociedades nacionais (RAWLS, 1993, p. 53).

Na segunda posição original (segundo nível), desenvolvida a partir da obra The Law of Peoples, os representantes racionais dos povos liberais pretendem estender uma concepção liberal ao Direito dos Povos, assim como fez o autor na primeira posição, sempre tendo presente que se está a tratar de um modelo de representação que modela o que se considera "[...] como condições justas sob as quais as partes, desta vez os representantes racionais de povos liberais, devem especificar o Direito dos Povos, guiados pelas razões adequadas" (RAWLS, p. 2001, p. 42). O objetivo principal é uma concepção política de justiça que garanta valores políticos, superando outros valores que, consequentemente, não entrariam na pauta de discussão para a construção de uma sociedade mais justa na esfera internacional.

\footnotetext{
${ }^{15}$ Expõe o autor que devem ser considerados cidadãos livres e iguais aqueles que possuem "[...] as faculdades de personalidade moral, quais sejam, a capacidade de ter senso de justiça e a capacidade de ter uma concepção de bem" (RAWLS, 1993, p. 78).
} 
A primeira posição original, no entanto, terá um papel importante para o Direito dos Povos. A partir dela, o direito e a justiça para as sociedades nacionais serão organizados com a elaboração dos princípios de justiça pelas partes representantes dos cidadãos. Os princípios limitam o poder dos Estados nacionais ao servirem de base para a construção de normas jurídicas que fundamentam o Estado Democrático de Direito em sociedades liberais.

Rawls busca romper, a partir da sua proposta de um Direito dos Povos, com a lógica de poder soberano ilimitado que, muitas vezes, serviu e serve de meio para a opressão no interior das sociedades nacionais. Sua intenção é de que os governos tenham seus poderes limitados de maneira a preservar os interesses dos indivíduos, tanto no âmbito nacional (PO1) quanto internacional (PO2). ${ }^{16}$

Nesse sentido, há uma relação entre ambas as posições (PO1 e PO2), assim como possíveis diferenças podem ser observadas. A PO1 servirá de guia para a PO2. Os princípios escoIhidos na PO1 representam interesses fundamentais das sociedades democráticas nacionais e fundamentam a escolha dos princípios para a Sociedade dos Povos na PO2. As diferenças entre ambas, conforme Rawls (2001), não estariam no modo como elas são usadas enquanto modelos de representação, mas na forma como cada uma se ajustará em razão dos agentes envolvidos e das questões relevantes para cada nível.

Consoante Rawls (2001, p. 43), na segunda posição original, a realizar-se no plano internacional, os representantes dos povos devem ser, obrigatoriamente, "(1) razoável e justamente situados como livres e iguais; [os] povos são (2) modelados como racionais [de maneira] (3) a [deliberar] a respeito do tema correto, neste caso o conteúdo do Direito dos Povos." Há, para tanto, uma espécie de Direito que estaria governando as estruturas básicas que compõem a relação entre os povos. "Além disso, (4) as suas deliberações prosseguem em termos das razões certas (como restritas por um véu de ignorância)"; nesse caso, o rol de princípios é escolhido a partir dos "(5) interesses fundamentais de um povo, dados, nesse caso, por uma concepção liberal de justiça (já selecionada na primeira posição original)."

Explicita o autor americano que "[...] o Direito dos Povos é desenvolvido dentro do liberalismo político, sendo o mesmo uma [...] extensão de uma concepção liberal de justiça de um regime nacional para uma Sociedade dos Povos." Nesse viés, Rawls propõe os seguintes princípios como fundamentais em uma sociedade dos Povos: 1 . Os povos são livres e independentes, e sua liberdade e independência devem ser respeitadas por outros povos; 2. Os povos devem observar tratados e compromissos; 3. Os povos são iguais e são partes em acordos que os obrigam; 4. Os povos sujeitam-se ao dever de não intervenção; 5 . Os povos têm o direito de autodefesa, mas nenhum direito de instigar a guerra por outras razões que não a autodefesa; 6. Os povos devem honrar os direitos humanos; 7. Os povos devem observar certas restrições especificadas na conduta da guerra; 8. Os povos têm o dever de assistir a outros povos vivendo sob condições desfavoráveis que os impeçam de ter um regime político e social justo ou decente (RAWLS, 2001, p. 47-48).

\footnotetext{
${ }^{6}$ Optamos por abreviar as expressões primeira posição original (PO1) e segunda posição original (PO2)
} 


\section{Humanos}

Democracia

Rawls (2001, p. 48) reconhece que tais princípios não estariam fechando a presente relação; outros poderiam ser acrescentados ampliando ainda mais o rol existente, assim como alguns seriam desnecessários em uma sociedade de povos bem-ordenados. ${ }^{17}$ Esse é o caso dos princípios sexto e sétimo que tratam, respectivamente, do respeito aos direitos humanos e sobre a conduta de guerra.

Dentre os princípios, aquele que apresenta maior fragilidade, na concepção do autor, seria o princípio quarto. "Embora adequado a uma sociedade de povos bem-ordenados, fracassa no caso de uma sociedade de povos desordenados, na qual as guerras e violações sérias dos direitos humanos são endêmicas." Ainda é possível citar o princípio primeiro - direito à independência e autodeterminação -, que também se tornaria frágil diante de condutas graves contra um povo, o que possibilitaria a sua violação como forma de restabelecer a ordem.

Por fim, o princípio oitavo, que se refere ao dever de assistência devida às sociedades em condições desfavoráveis, que rende muitas críticas relativas a sua extensão e possível cumprimento. ${ }^{18}$

\section{CONSIDERAÇÕES FINAIS}

Nesse contexto, a proposta rawlsiana de uma Lei dos Povos, que tem por base uma concepção política liberal de direito e de justiça, foi por alguns autores denominada de etnocêntrica e essencialmente ocidental, um "imperialismo cultural" e, até mesmo, "perigosamente universalista". As críticas, na maioria das vezes, partiram de autores com tendência cosmopolita, como C. R. Beitz (1999) e T. W. Pogge $\left(1994,2007 .{ }^{19}\right.$

Para Audard (2006, p. 36, grifo do autor), no entanto, que sai em defesa da proposta rawlsiana de justiça para a Sociedade dos Povos, o autor delimita o alcance da sua teoria, ao contrário do que os críticos pensavam. Compreende a autora que em The Law of Peoples, "[...] Rawls está preocupado principalmente com a justiça entre sociedades, não com a justiça dentro de sociedades, embora, para muitas pessoas, as duas estejam profundamente conectadas."

Entendemos, porém, e essa é uma visão construída a partir do presente estudo, que há uma relação intrínseca entre ambas as propostas de justiça, tanto para as sociedades nacionais quanto para as sociedades no âmbito internacional, e essa conexão é possível de ser percebida, principalmente, quando o autor trata do dever de assistência.

Acreditamos, também, que a ideia de reciprocidade, autodeterminação e respeito, presentes como elementos fundamentais para uma Sociedade dos Povos, garante, desde o princípio, uma saída para o autor com relação à acusação que lhe é imposta de promoção de uma espécie de "imperialismo cultural". Parece-nos muito mais evidente que desde o princípio está clara a preocupação e o empenho de Rawls na construção de um projeto de justiça social que garantirá a paz e a estabilidade requerida para uma Sociedade dos Povos.

\footnotetext{
${ }_{17}$ Cabe destacar aqui que o princípio que se refere à assistência somente veio a ser inserido na última versão de The Law of Peoples (1999).

${ }^{18}$ Rawls (2001, p. 52) afirma "que os oito princípios do Direito dos Povos são superiores a quaisquer outros. De maneira muito semelhante a como examinamos os princípios distributivos na justiça como equidade, começamos com a diretriz básica da igualdade - no caso da justiça como equidade, a igualdade de bens primários sociais e econômicos; neste caso, a igualdade de todos os povos e os seus iguais direitos."

${ }^{19}$ Para uma maior compreensão da teoria dos autores, consultar obras indicadas na bibliografia ao final do presente estudo.
} 


\section{REFERÊNCIAS}

AUDARD, Catherine. Cidadania e democracia deliberativa. Tradução Walter Valdevino. Porto Alegre: EDIPUCRS, 2006.

BEITZ, C. R. Liberalismo Internacional e Justiça Distributiva. In: Lua Nova, Revista de Cultura e Política, n. 47, p. 27-58, 1999.

CABRITA. M. J. Os desígnios da democracia global internacional na utopia realista rawlsiana. In: COSTA, Marta Nunes da (org.). Democracia hoje. Famalicão, Portugal: Húmus; CEH-UM, 2012.

KANT, I. A paz perpétua e outros opúsculos. Lisboa: Edições 70, 2002.

RAWLS, J. O Direito dos povos. Tradução Luís Carlos Borges. São Paulo: Martins Fontes, 2001.

RAWLS, J. The Law of Peoples; With the idea of Public Reason Revised. Second printing. Harvard: Harvard University Press, 2000.

RAWLS, J. Political Liberalism. New York: Columbia University Press, 1993.

RAWLS, J. O liberalismo político. Edição ampliada. Tradução Álvaro de Vita. São Paulo: Martins Fontes, 2011.

RAWLS, J. O liberalismo político. Tradução Dinah de Abreu Azevedo. 2. ed. São Paulo: Ática, 2000.

RAWLS, J. A Theory of Justice. Revised Edition. Cambridge, Massachusetts: Harvard University Press, 1999.

OLIVEIRA, N. de. Rawls. Rio de Janeiro: Jorge Zahar Ed., 2003.

OLIVEIRA, N. de. Kant, Rawls e a fundamentação de uma teoria da justiça. In: FELIPE, S. T. (org.). Justiça como equidade: fundamentações e interlocuções polêmicas (Kant, Rawls, Habermas). Florianópolis: Insular, 1998.

PETTIT, P. Rawls's Peoples. In: MARTIN, R.; REIDY, D. Rawls's Law of Peoples: A Realistic Utopia? Oxford: Blackwell Publishing, 2007.

POGGE, T. W. Uma proposta de reforma: um dividendo global de recursos. In: Lua Nova, Revista de Cultura e Política, n. 34, p. 135-161, 1994.

POGGE, T. W. Para erradicar a pobreza sistêmica: em defesa de um dividendo dos recursos globais. In: Sur, Revista Internacional de Direitos Humanos, v. 4, n. 6, p. 142-166, 2007. 